\title{
RANCANG BANGUN BEAMFORMING SENSOR PADA SISTEM AKUSTIK BAWAH AIR
}

\author{
SENSOR BEAMFORMING DESIGN ON UNDER WATER ACOUSTIC SYSTEM \\ Supartono ${ }^{1}$, Rusmana ${ }^{1}$ \\ ${ }^{1}$ Sekolah Staf Komando Angkatan Laut \\ Korespondensi : tonnret@yahoo.com
}

\begin{abstract}
Beamforming is the method used to create the radiation pattern of the antenna array by adding constructively the phases of the signals in the direction of the targets, and nulling the pattern of the interfing targets. Signal processing technique used is array sensors technology to create the transmission or reception of directional signal. Beamforming technique in underwater acoustics has been developed for a long time for the purposes of sonar, seismology, underwater communication, and identification of sound sources or submarines noise. If beamforming technique is used, so the signal strength, which is transmitted or percepted in a particular direction, will be much greater than the omnidirectional method or spherical sensors. Mastering the underwater technology is strategic, both simple technology and complex one, such as sonar or torpedo and the submarine. Countries mastering underwater technology will have the predominance in submarine warfare. Having a confidential nature and shocking system is a benefit of underwater weapon. Regarding to the mentioned problems, the study of beamforming sensor design was conducted with the expectations that the next generation of Indonesia can build the main instrument of defense system strength based on the strength of their own nation.
\end{abstract}

Keywords: beamforming, communication underwater, sonar

\begin{abstract}
ABSTRAK
Beamforming adalah sebuah metode yang digunakan untuk membuat pola radiasi dari antena array dengan cara menambahkan konstruksi dari fasa sebuah sinyal pada arah target yang menginginkan bergerak, dan nulling pola dari target yang interfering target. Teknik pemrosesan sinyal yang digunakan adalah teknologi sensor terangkai (array sensors) untuk menciptakan transmisi atau resepsi sinyal yang terarah. Teknik beamforming dalam akustik bawah air (underwater acoustics) telah dikembangkan sejak lama untuk keperluan sonar, seismologi, komunikasi bawah air serta identifikasi sumber suara atau bising kapal selam. Melalui teknik beamforming maka kuat sinyal yang ditransmisikan atau dipersepsi pada arah tertentu akan jauh lebih besar dibandingkan dengan metode omni drectional atau spherical sensors. Penguasaan teknologi bawah air bersifat strategis, apapun jenisnya baik yang sederhana maupun yang kompleks seperti sonar atau torpedo maupun kapal selam. Hanya negara-negara yang menguasai ilmu pengetahuan dan teknologi dasar bawah air akan memiliki keunggulan dalam peperangan bawah permukaan. Sistem senjata bawah air memiliki sifat kerahasiaan dan pendadakan yang sangat menguntungkan. Berlatarbelakang dari permasalahan tersebut di atas, penelitian rancang bangun sensor beamforming dilakukan dengan harapan putra-putri bangsa Indonesia dapat membangun kekuatan alutsita pertahanan dengan kekuatan bangsa sendiri.
\end{abstract}

Kata kunci: beamforming, komunikasi bawah air, sonar 


\section{PENDAHULUAN}

Konsep pertahanan yang ideal bagi suatu negara, harus dapat mengeksploitasi keadaan-keadaan fisik dan non-fisik negara tersebut sehingga dapat menimbulkan keunggulan-keunggulan yang mampu dimanfaatkan untuk melemahkan dan mengalahkan musuh. Berdasarkan pada kondisi geografis Indonesia, utamanya aspek hidro-oseanografi, maka konsep pertahanan laut Indonesia akan sangat relevan apabila mengarah pada "Konsep peperangan bawah air" baik peperangan kapal selam dan kapal anti-selam maupun peperangan ranjau dan anti-ranjau. Saat ini negara-negara sekawasan telah membangun kekuatan armadanya dengan membeli beberapa buah kapal selam lengkap dengan sistem senjata utamanya yaitu torpedo, demikian pula dengan kapal-kapal penyebar dan buru ranjaunya yang cukup handal didukung peralatan dengan teknologi mutakhir.

Penguasaan teknologi bawah air bersifat strategis, apapun jenisnya baik yang sederhana maupun yang kompleks seperti sonar atau torpedo maupun kapal selam. Karakteristik media air laut cukup kompleks untuk dimodelkan secara matematis sehingga tingkat kesulitan dalam aplikasi teknologi di bawah air juga tinggi. Hanya negara-negara yang menguasai ilmu pengetahuan dan teknologi dasar bawah air (seperti oseanografi) akan memiliki keunggulan. Pada aplikasi militer sistem senjata bawah air memiliki sifat kerahasiaan dan pendadakan yang sangat menguntungkan.

Beamforming adalah sebuah metode yang digunakan untuk membuat pola radiasi dari antena array dengan cara menambahkan konstruksi dari phasa sebuah sinyal pada arah target yang menginginkan bergerak, dan nulling poladari target yang interfering target. Teknik pemrosesan sinyal yang digunakan adalah teknologi sensor terangkai (array sensors) untuk menciptakan transmisi atau resepsi sinyal yang terarah. Teknik beamforming dalam akustik bawah air (underwater acoustics) telah dikembangkan sejak lama untuk keperluan sonar, seismologi, komunikasi bawah air serta identifikasi sumber suara atau bising kapal selam. Melalui teknik beamforming maka kuat sinyal yang ditransmisikan atau dipersepsi pada arah tertentu akan jauh lebih besar dibandingkan dengan metode omnidrectional atau spherical sensors.
Teknik beamforming dalam underwater acoustics dianggap memiliki beberapa keunggulan dibandingkan dengan penggunaan sinyal elektromagnetik yang akan mengalami pelemahan sangat besar selama berpropagasi dalam air atau sinyal optik yang akan mengalami banyak scattering oleh partikelpartikel di dalam air atau dipengaruhi oleh intensitas cahaya ambien yang relatif tinggi. Walaupun demikian, pemanfaatan teknik beamforming untuk kondisi riil akustik bawah air sangat dipengaruhi oleh dinamika fisis lingkungan di bawah permukaan air yang selalu mengalami perubahan spasial dan temporal (temporal and spatially varying environment) sehingga hampir tidak ditemui suatu kondisi fisis medium yang tipikal. Hal ini memberikan tantangan tersediri dalam pemanfaatan teknik beamforming di bawah permukaan air, sehingga keberhasilan pemanfatan teknik beamforming untuk pengembangan sensor akustik bawah air secara paralel memerlukan pemahaman tentang sifat-sifat propagasi gelombang akustik dalam medium air.

Rancangan komponen yang dibutuhkan oleh suatu perangkat sensor beamforming tergantung dari jenis sensor tersebut. Single beamforming menggunakan satu sensor pemancar atau penerima sinyal yang dilengkapi dengan piringan pengumpul sinyal seperti pada sistem radar, sedangkan untuk sistem deteksi bawah air (sonar) merupakan jenis multiple sensors yang menggunakan lebih dari satu sensor yang dapat dirangkai sesuai dengan bentuk beamforming yang dibutuhkan. Secara umum diagram blok suatu sistem sensor beamforming dapat dilihat pada Gambar 1 .

Jika sumber suara mempunyai posisi jarak cukup jauh dari sensor penerima (hydrophone), maka garis penjalaran gelombang suara yang datang pada dua titik yang berdekatan dapat dianggap paralel (plane wave). Sehingga, jika suatu sumber suara tersebut terletak pada suatu garis yang normal (tegak lurus) terhadap suatu garis/bidang datar yang melalui dua buah sensor, maka tidak terdapat perbedaan waktu tempuh gelombang suara yang datang dari sumber suara tersebut hingga diterima oleh ke dua sensor. Sebaliknya, jika sudut datang (angle of arrival, AoA) adalah [radians] terhadap sumbu normal, maka perbedaan waktu tempuh (waktu datang) untuk mencapai dua hydrophone yang berdekatan adalah: 


$$
\tau(\theta)=\frac{d \sin \theta}{v}
$$

d adalah jarak antar hydrophone (meter), sedangkan $v$ adalah kecepatan suara di dalam air (meter/detik).

Jika sumber suara mempunyai posisi jarak cukup jauh dari sensor penerima (hydrophone), maka garis penjalaran gelombang suara yang datang pada dua hydrophone yang berdekatan dapat dianggap paralel (plane wave). Sehingga, jika suatu sumber suara terletak pada suatu garis yang tegak lurus (normal) terhadap suatu garis/ bidang datar yang melalui dua buah sensor, maka tidak terdapat perbedaan waktu tempuh (waktu datang) gelombang suara yang datang dari sumber suara tersebut hingga diterima oleh ke dua sensor.

Dalam penelitian dikembangkan prototipe sonar beamforming satu dimensi dengan coverage sudut deteksi tidak kurang dari dengan resolusi tidak lebh dari $10^{\circ}$. Sekurang-kurangnya, dari penelitian ini dapat dikuasai pengetahuan serta teknologi sonar beamforming guna meningkatkan resolusi coverage yang lebih akurat. Prototipe sonar beamforming terdiri dari atas hydrophone array, realtime signal processor, dan data display.

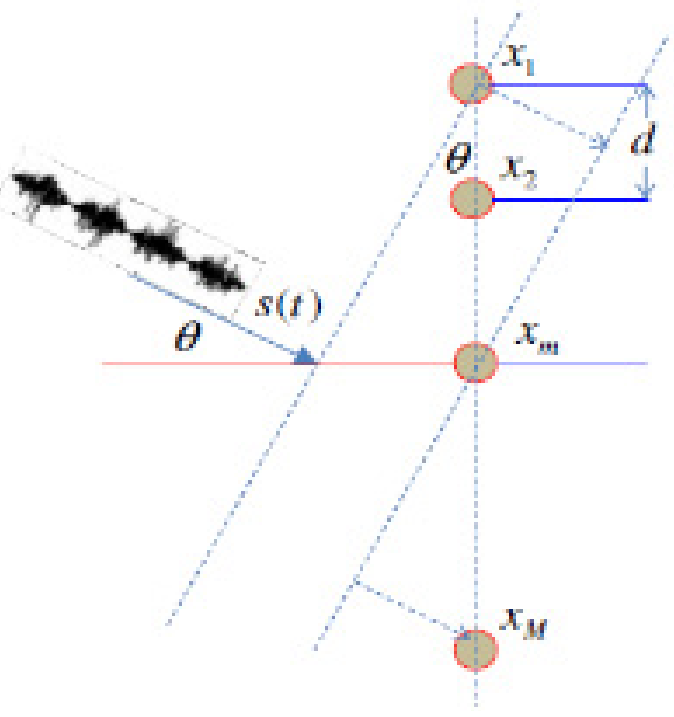

Gambar 1. Struktur hydrophone array pada sonar beamforming

\section{METODE PENELITIAN}

Penelitian rancang bangun prototip dibatasi pada satu dimensi dengan coverage sudut datang sebagaimana disebutkan: serta resolusi kurang dari $10^{\circ}$, yang diperoleh dengan 16 hydrophone. Dalam penelitian ini belum diberikan kompensasi temperatur lingkungan serta kedalaman bawah air terhadap arah serta kecepatan perambatan gelombang suara bawah air (underwater sound speed). Diasumsikan dalam penelitian ini hanya terdapat satu sumber suara yang datang dari arah bidang horisontal. Dalam penelitian ini hydrophones yang digunakan sebanyak 16 buah, dari 32 yang direncanakan, karena harga dari sebuah hydrophones dan perangkat sistem pengolah sinyal yang relatif mahal.

Selanjutnya, diagram blok sistem sonar beamforming yang direalisasikan pada penelitian ini ditunjukkan pada Gambar 2. Output dari masing-masing hydrophone diberikan kepada analog-to-digital converter (ADC), untuk kemudian diproses di dalam sebuah embedded computer. Hasil pengolahan sinyal real-time selanjutnya diperagakan pada layar komputer. Komponen-komponen yang diguna-kan pada sistem Beamforming sinyal akustik bawah air, ditujukan pada Tabel 1 . 

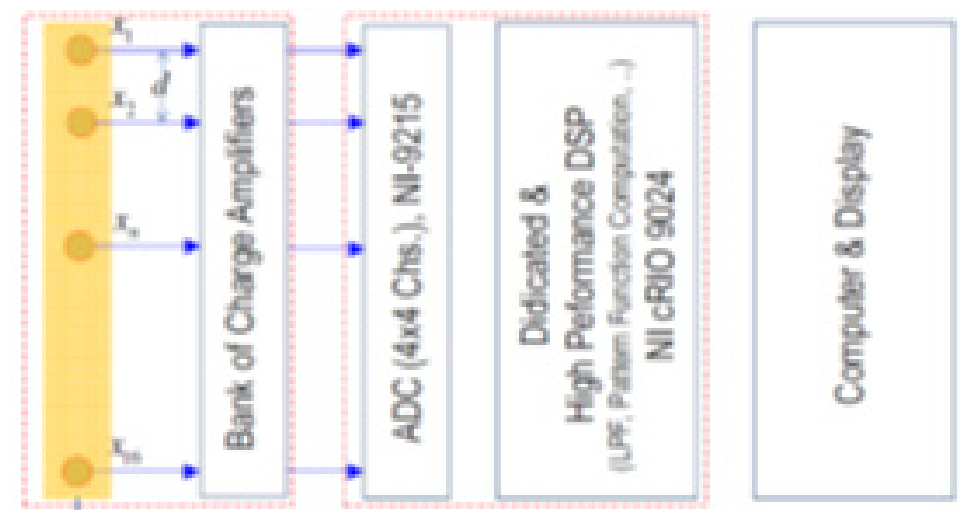

Gambar 2. Diagram blok sistem sonar beamforming yang dibuat dalam penelitian ini

Tabel 1. Komponen yang digunakan untuk sistem Beamforming

\begin{tabular}{|c|c|c|c|c|}
\hline No. & Nama & Tipe & Jumlah & Uraian \\
\hline 1 & Hydrophone & $\begin{array}{l}\text { BII-7032 (Type 1), Benthowave } \\
\text { Instruments Inc }\end{array}$ & 16 & $\begin{array}{l}\text {-omnidirectional type } \\
\text {-including preamplifier } \\
\text {-bandwidth } 0-60 \mathrm{kHz}\end{array}$ \\
\hline 2 & ADC 4 Channels & NI 9215, National Instrument & 4 & $\begin{array}{l}-16 \mathrm{bit} \\
-100 \mathrm{kS} / \mathrm{s} / \mathrm{Ch} \\
+/-10 \text { volts }\end{array}$ \\
\hline 3 & $\begin{array}{l}\text { Real Time Power } \\
\text { PC Controller }\end{array}$ & $\begin{array}{l}\text { NI cRIO-9024, } \\
\text { National Instrument }\end{array}$ & 1 & $\begin{array}{l}-800 \mathrm{MHz} \\
-4 \mathrm{~GB} \text { Storage } \\
-512 \mathrm{MB} \text { DRAM }\end{array}$ \\
\hline 4 & Keypad \& Display & Laptop 13" & 1 & Toshiba \\
\hline 5 & Power Supplay & & 1 & 24 Volts DC, 100 Watts \\
\hline
\end{tabular}

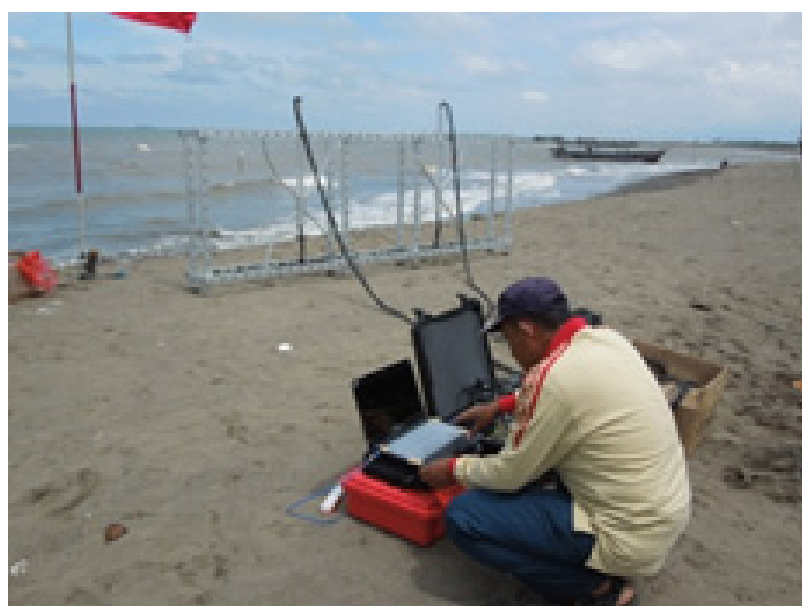

Gambar 3. Instalasi sistem secara keseluruhan sebelum array dimasukkan ke dalam laut 

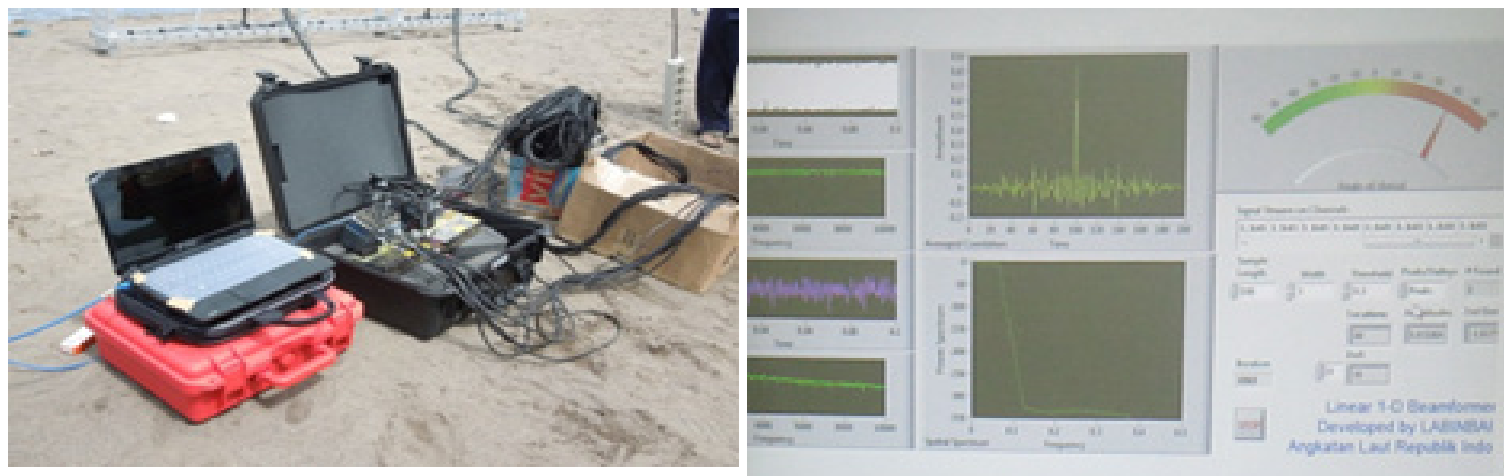

Gambar 4. Komponen utama pengolah sinyal akustik yang diterima dari array hydrophones (kiri) dan tampilan display-nya (kanan)

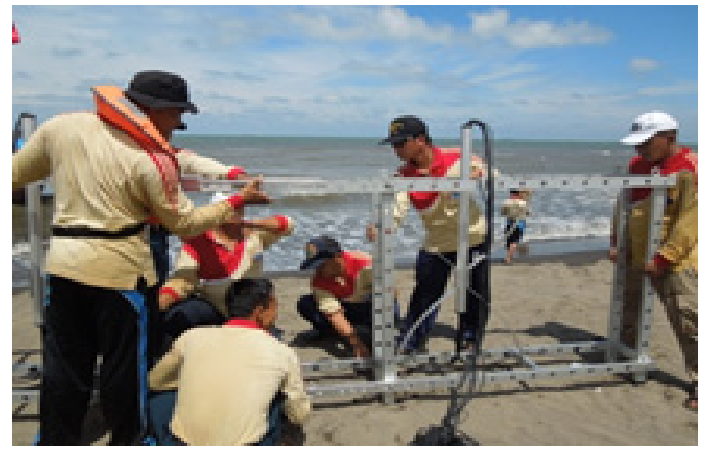

Gambar 5. Instalasi array sensor hydrophones
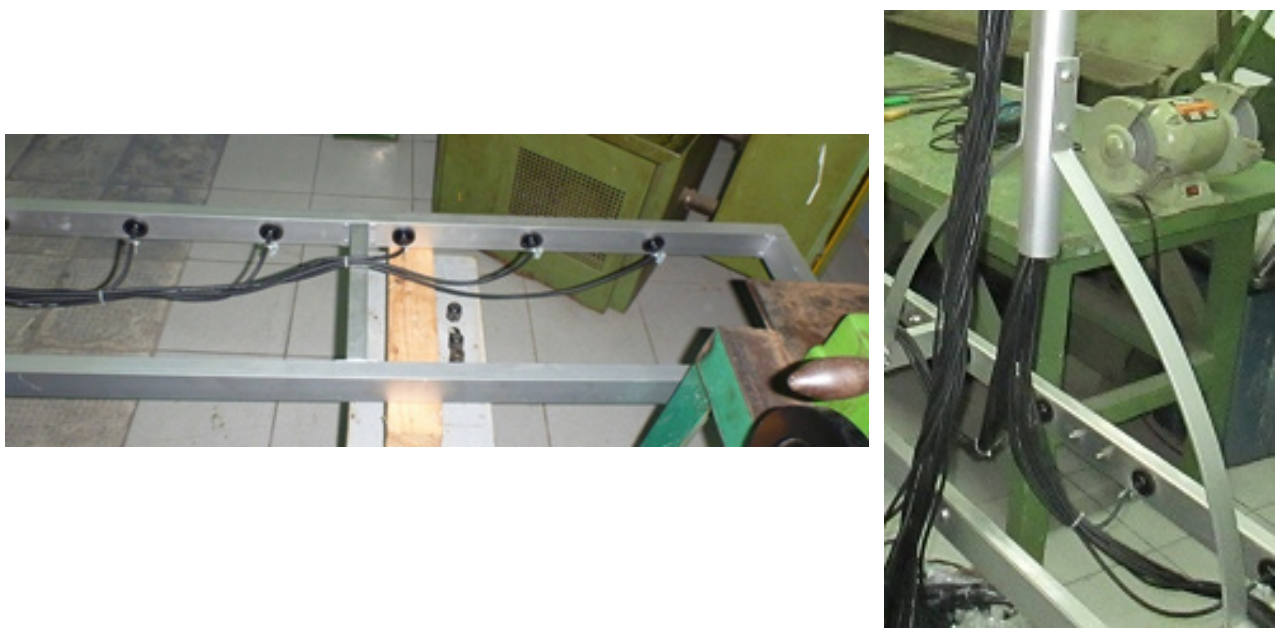

Gambar 6. array sensor akustik, tersusun dari beberapa hydrophones dengan jarak antarsensor $20 \mathrm{~cm}$

\section{HASIL DAN PEMBAHASAN}

Jika dilihat dari skematik di atas (gambar 2) untuk pengembangan sistem pengolahan sinyal dengan beamforming terdapat beberapa sub-sub sistem. Dengan perkembangan teknologi komputer dan elektronika, subsub sistem tersebut dapat dibangun secara "compact" dan diolah menggunakan software yang akurat dan presisi sehingga dapat menekan noise atau memperbesar nilai rasio
S/R (Signal to Noise Ratio). Oleh karena itu dalam system beamforming yang dikembangan sensor hydrophone dihubungkan langsung ke sebuah "embeded computer" dengan 16 channel menggunakan kabel $15 \mathrm{~m}$. Dalam embeded computer tersebut telah terdapat signal conditioning, ADC, signal processor dan selanjutnya display (monitor) akan menampilan informasi berupa spectrum sinyal yang ditangkap, arah sumber sinyal, jumlah sinyal yang diterima. 


\section{KESIMPULAN DAN SARAN}

\section{Kesimpulan}

Sistem deteksi bawah air dengan teknik beamforming ini dibangun atas sub-sub sistem yang terdiri array 16 buah hydrophones, embedded computer yang merupakan integrasi dari penguat sinyal, analog to digital converter (ADC), signal conditioning, filter serta prosesor yang didukung oleh software guna mengolah berbagai algoritma yang digunakan sehingga sinyal yang diterima dapat diketahui spektrumnya dan arah datangnya untuk dapat ditampilkan dalam monitor.

Pengolahan sinyal akustik bawah air menggunakan metode beamforming merupakan teknik dasar yang banyak digunakan dari berbagai sistem deteksi bawah air. Sehingga penelitian ini dapat dikembangkan untuk berbagai aplikasi deteksi bawah air seperti sonar, seeker torpedo, sonobuoy, flank array sonar dan sebagainya.

\section{Saran}

Kegiatan penelitian beamforming ini dapat dikembangkan untuk penelitian aplikasi lainnya yang terkait dengan sistem deteksi bawah air bagi berbagai alutsista TNI AL. Untuk lebih berhasil guna kegiatan penelitian aplikasi beamforming dilaksanakan dalam masing-masing fokus kegiatan dan tujuan.

Kegiatan penelitian aplikasi dari teknik beamforming dalam detkasi bawah air dapat dilaksanakan dengan melibatkan komponen lain seperti perguruan tinggi, industri dan lembaga lainnya (mis. BPPH/Hidrodinamika BPPT), dengan diawali kegiatan workshop/ diskusi teknis serta penyusunan road map.

\section{DAFTAR PUSTAKA}

Balanis CA. 1982. Antena Theory: Analysis and Design. Harper \& Row: New York.

Godara LC. 1997. Applications of antenna array to mobile communications. Proceedings of the IEEE. VOL. 85, Hal: 1032-1060.

Joseph CL, Rappaport TS. 1998. Smart antennas for wireless communications, Prentice Hall PTR: New York.

Kohno R. 1998. Spatial and temporal communications theory using adaptive antenna arary. Proceedings of the IEEE. VOL. 85

Widrow, Stearns. 1985. Adaptive signal processing. Prentice Hall PTR : New York.

Aswoyo B, Basuki A. 2001. Optimization array factor of planar array antenna using genetic algorithms. Proceeding of the International Conference on Electrical, Electronics, Communication, and Information (CECI2O01). 